\title{
Genetics of resistance to common root rot (spot blotch), Fusarium crown rot, and sharp eyespot in wheat
}

\author{
Jun Su ${ }^{1, \uparrow}$, Jiaojie Zhao ${ }^{1, \uparrow}$, Shuqing Zhao ${ }^{1, \uparrow}$, Mengyu Li ${ }^{1}$, Shuyong Pang ${ }^{1,4}$, Shisheng Chen ${ }^{4}$, Feng \\ Chen ${ }^{5}$, Wenchao Zhen ${ }^{3, *}$, Zhensheng Kang ${ }^{2, *}$, Xiaodong Wang ${ }^{1, *}$ \\ ${ }^{1}$ State Key Laboratory of North China Crop Improvement and Regulation / College of Plant Protection, \\ Hebei Agricultural University, Baoding, Hebei 071000, P. R. China; \\ ${ }^{2}$ State Key Laboratory of Crop Stress Biology for Arid Areas / College of Plant Protection, Northwest \\ A\&F University, Yangling, Shaanxi 712100, P. R. China; \\ ${ }^{3}$ College of Agronomy, Hebei Agricultural University, Baoding, Hebei 071000, P. R. China; \\ ${ }^{4}$ Institute of Advanced Agricultural Sciences, Peking University, Weifang, Shandong 261000, P. R. \\ China; \\ ${ }^{5}$ National Key Laboratory of Wheat and Maize Crop Science / Agronomy College, Henan Agricultural \\ University, Zhengzhou 450046, P. R. China; \\ * Correspondence: Xiaodong Wang (zhbwxd@hebau.edu.cn), Zhensheng Kang \\ (kangzs@nwsuaf.edu.cn), and Wenchao Zhen (wenchao@hebau.edu.cn) \\ $\dagger$ These authors contributed equally to this work.
}

Abstract: Due to soil changes, high density planting, and the use of straw-returning methods, wheat common root rot (spot blotch), Fusarium crown rot (FCR), and sharp eyespot (sheath blight) have become severe threats to global wheat production. Only a few wheat genotypes show moderate resistance to these root and crown rot fungal diseases, and the genetic determinants of wheat resistance to these devastating diseases are poorly understood. This review summarizes recent results of genetic studies of wheat resistance to common root rot, Fusarium crown rot, and sharp eyespot. Wheat germplasm with relatively higher resistance are highlighted and genetic loci controlling the resistance to each disease are summarized.

Keywords: wheat, resistance, common rot root, spot blotch, Fusarium crown rot, sharp eyespot

\section{Introduction}

Long-term environmental changes have greatly affected crop diseases. For example, the higher temperatures associated with global warming may increase the severity of many plant diseases (Cohen and Leach 2020). Bursts of wheat stem base rot diseases, including common root rot, Fusarium crown rot, and sharp eyespot, are highly correlated with crop rotation practices. The large-scale application of wheat-maize rotation in the North China wheat cultivation area has dramatically changed the organic carbon, fertilization state, and nitrogen balance of the soil (Wang et al. 2015; Zhao et al. 2006). The disease suppressive capacity of the soil microbiome is also highly dependent on crop rotational diversity (Peralta et al. 2018). 


\section{Pathogenic profiles}

Wheat common root rot is caused by Bipolaris sorokiniana infection (Fig. 1a, teleomorph Cochliobolus sativus) in the root and stem base of wheat plants. Severe infections of this fungal pathogen in the root and crown of seedlings may kill plants. B. sorokiniana can also induce phenotypes of leaf spot (spot blotch, Helminthosporium leaf blight, or foliar blight, Fig. 1b), seedling wilt, head blight, and black point in Triticeae crops (Kumar et al. 2002). The average yield loss caused by B. sorokiniana ranges from $15 \%$ to $20 \%$, but under favorable heat and drought conditions this disease can decrease wheat production by $70 \%$ and reduce seed quality (Sharma and Duveiller 2007). This fungal pathogen accumulates several toxins to kill or weaken plant cells, including prehelminthosporol, helminthosporol, helminthosporic acid, sorokinianin, and bipolaroxin (Kumar et al. 2002; Gupta et al. 2018). However, the potential negative effects of B. sorokiniana-infected wheat grains (black point) on food safety have not been investigated in detail. B. sorokiniana has a very wide host range, as it can infect wheat, barley, maize, rice, and many other grass species (Gupta et al. 2018). Multiple-year Triticeae crop rotations of wheat and barley greatly promote the severity of common root rot caused by B. sorokiniana (Conner et al. 1996). Maize crops and returned straws may also be infected by this fungus, so common root rot and spot blotch have been more frequently observed in areas of wheat cultivation in North China where methods of large-scale wheat-maize rotation and straw returning have been applied.

Fusarium crown rot (FCR) is caused by infection of Fusarium pseudograminearum (Fig. 1c), or other Fusarium pathogens including F. culmorum, F. avenaceum, and F. graminearum. These fungal species infect the coleoptile, leaf sheath, and stem base of wheat seedlings, generating browning and decay phenotypes (Fig. 1d). Fusarium pathogens are found globally in arid and semi-arid wheat planting areas (Kazan and Gardiner 2018). FCR infection caused an estimated $35 \%$ yield loss of winter wheat in the Northwest Pacific region of the United States (Smiley et al. 2005). When FCR-infected plants are co-infected with Fusarium Head Blight (FHB), wheat seeds are likely to be contaminated by fungal toxins such as deoxynivalenol (DON) and nivalenol (NIV), which greatly threaten the health of human and livestock (Obanor and Chakraborty 2014; Monds et al. 2005). Maize also can be infected with various Fusarium 
pathogens, and the fungi from infected plants can remain active in returned straw debris for as long as five years (Burgess et al. 2001). For these reasons, FCR is a growing threat to wheat cultivation in wheat-maize rotation regions in North China.

Wheat sharp eyespot (sheath blight) is caused by infection of Rhizoctonia cerealis (Fig. 1e) in the root and stem base of wheat plants, generating disease phenotypes of stem eyespot (Fig. 1f), crown rot, seedling fatal damage, and head blight. Wheat sharp eyespot is a typical soilborne fungal disease that is prevalent worldwide (Hamada et al. 2011). R. cerealis also has a broad host range, including many cereals. This fungal pathogen can survive in soil or on infected crop residues for a long time. Consequently, practices of wheat-maize rotation and straw-returning have greatly facilitated the burst of this disease in China during the last two decades (Ren et al. 2020). In 2005, approximately 8 million ha of wheat fields in China were infected with sharp eyespot, with an estimated yield loss of about 530,000 tons (McBeath and McBeath 2010). Sharp eyespot also significantly decreases wheat grain quality (Lemańczyk and Kwaśna 2013).

These three diseases can have similar phenotypes, causing stem base rot and head blight, but there are differences as well. Common root rot caused by $B$. sorokiniana weakens infected wheat plants so they can be easily pulled out. Additionally the stem base and root system feel wet, and black and brown striped spots form on both the stem base and lower leaves (Fig. 1b). For FCR caused by F. pseudograminearum, the stem base of the infected wheat plant becomes dry and fragile, and dark brown rot can be observed in the stem base (Fig. 1d). For sharp eyespot caused by $R$. cerealis, most lesions on the wheat stem are elliptical or have a "eye" shape, with sharply dark brown borders (Fig. 1f).

\section{Progress in dissecting the genetic determinants of wheat resistance to common root rot (spot blotch)}

The use of wheat resistant cultivars remains the most efficient and economical way to control common root rot (spot blotch). However, there are currently insufficient germplasm resources with resistance to common root rot to meet the growing needs for global wheat breeding applications and there have been few studies to identify the genetic loci that control resistance to common root rot (Gupta et al. 2018). Early efforts focused on the introgression of common 
root rot resistant loci from Thinopyrum ponticum, a wheat relative (Li et al. 2004). Wheat breeding programs for common root rot resistance have had limited success because analysis of complex quantitative trait loci (QTL) is required (Joshi et al. 2004). Using bi-parental populations and linkage mapping, four genetic loci with major resistant effect were identified and designated as $S b$ genes. $S b 1$ was discovered in the bread wheat line "Saar", was mapped to chromosome 7DS, and is associated with the wheat leaf rust resistance gene Lr34 (Lillemo et al. 2013). The $\operatorname{Lr} 34 / \operatorname{Yr} 18 / \mathrm{Pm} 38$ gene encodes a ATP-binding cassette (ABC) transporter that confers broad-spectrum resistance to multiple foliar fungal diseases, including leaf rust, stripe rust, and powdery mildew (Krattinger et al. 2009). Another minor QTL linked to $L r 46$ on chromosome 1BL was also identified from "Saar". The $L r 46$ gene is associated with resistance to leaf rust in adult plants and is also associated with the stripe rust resistance gene $\operatorname{Yr} 29$ (William et al. 2003). The Sb2 gene was identified in bread wheat cultivar "Yangmai 6" and was mapped to chromosome 5BL between simple sequence repeat (SSR) markers of Xgwm639 and $X g w m 1043$ (Kumar et al. 2015). The $S b 2$ gene was later reported to be linked with the Tsn 1 gene, which confers host-selective sensitivity to the fungal toxin ToxA produced by Pyrenophora tritici-repentis (Kumar et al. 2016). The Sb3 gene was discovered in the winter wheat line "621-7-1" based on its correlation with immune response to B. sorokiniana. Using bulked segregant analysis (BSA), Sb3 was mapped to chromosome 3BS, flanking SSR markers of $X$ barc133 and Xbarc147 (Lu et al. 2016). The Sb4 gene was recently identified from two highly resistant wheat lines, “Zhongyu1211” and "GY17”. Using RNA-based BSA and singlenucleotide polymorphism (SNP) mapping, $S b 4$ was delimitated to a $1.19 \mathrm{cM}$ genetic interval region of chromosome 4BL, which contains 21 predicted genes in the corresponding "Chinese Spring" genome (Zhang et al. 2020). Future work should clone these $S b$ genes to further elucidate the mechanism of wheat resistance toward this devastating fungal pathogen.

Several other major QTLs have been discovered and preliminarily mapped using bi-parental populations. For example, two resistant QTLs derived from "Yangmai 6" were mapped to chromosomes 5B and 7D using microsatellite markers (Kumar et al. 2005). Three QTLs on chromosomes 5B, 6A, and 6D were identified based on analysis of SSR markers from the resistant genotype "G162” (Sharma et al. 2007). Four QTLs controlling resistance of wheat cultivar "Yangmai 6" to B. sorokiniana were mapped to chromosomes 2AL, 2BS, 5BL, and 
6DL (Kumar et al. 2009). A total of seven QTLs providing resistance to B. sorokiniana infections were mapped in the wheat lines "Ning 8201" and "Chirya 3" (Kumar et al. 2010). Three QTLs on chromosomes 1BS, 3BS, and 5AS respectively explained 8.5\%, 17.6\%, and $12.3 \%$, of the resistant effect in "SYN1", a CIMMYT (International Maize and Wheat Improvement Center) synthetic-derived bread wheat line (Zhu et al. 2014). From the Brazilian resistant cultivar "BH 1146", two QTLs on chromosomes 7BL and 7DL were mapped using microsatellite markers (Singh et al. 2016). A prominent resistant QTL near the Vrn-Al locus on chromosome 5AL was also found in "BARTAI" and "WUYA" CIMMYT breeding lines (Singh et al. 2018). Finally, QTLs in Vrn-A1 and Sb2/Tsn1 loci were detected in two other CIMMYT breeding lines, "CASCABEL" and "KATH" (He et al.).

Genome-wide association studies (GWAS) have been widely used to identify QTLs. Using 832 polymorphic Diversity Arrays Technology (DArT) markers, four QTLs resistant to spot blotch were mapped to chromosomes $1 \mathrm{~A}, 3 \mathrm{~B}, 7 \mathrm{~B}$, and 7D after analysis of 566 spring wheat germplasm (Adhikari et al. 2012). A phenotypic screening of 11 parental genotypes and $55 \mathrm{~F}_{2}$ lines identified "19HRWSN6" as a resistant source. Subsequent simple linear regression analysis revealed SSR markers on chromosomes 5B, 6A, and 7D associated with resistance to B. sorokiniana (Tembo et al. 2017). There has been recent progress in drafting the physical genome of hexaploid wheat (Appels et al. 2018), and high-throughput SNP toolkits are now available for GWAS on various complex traits of wheat (Sun et al. 2020). A total of 528 spring wheat genotypes from different geographic regions were tested for spot blotch resistance and eleven associated SNP markers were found by 9K SNP assay (Gurung et al. 2014). Another study evaluated the responses of 294 hard winter wheat genotypes to B. sorokiniana and performed GWAS by $15 \mathrm{~K}$ SNP assay. Ten wheat genotypes with relatively high resistance were identified, and six major resistant QTLs were found to collectively explain $30 \%$ of the phenotypic variation (Ayana et al. 2018). A total of 159 spring wheat genotypes were screened for common root rot resistance and twenty-four QTLs were identified, with a major one on chromosome 7B that explained 14\% of the phenotypic variation of spot blotch severity (Jamil et al. 2018). Another study profiled the resistant phenotype of 287 spring wheat germplasm and performed GWAS using 90K SNP array. Eight genetic loci were associated with incubation period, lesion number, and disease score of B. sorokiniana infection (Ahirwar et al. 2018). A 
recent study phenotyped 301 Afghan wheat germplasm and found that approximately $15 \%$ exhibited lower disease scores than the resistant control. A subsequent GWAS approach identified twenty-five marker-trait associations on more than twelve chromosomes, including previously identified $V r n-A 1$ and Sb2/Tsn1 loci (Bainsla et al.). Another 141 spring wheat lines were collected for GWAS on spot blotch resistance. A total of 23 genomic regions were identified, including several stable regions on chromosomes $2 \mathrm{~B}, 5 \mathrm{~B}$ and $7 \mathrm{D}$, and a novel region on chromosome 3D (Tomar et al. 2020).

We have summarized the previously reported wheat germplasm with relatively higher resistance to B. sorokiniana (Supplementary Table 1). These wheat materials may serve as valuable resources for the genetic improvement of wheat resistance to common root rot (spot blotch). We have also summarized detailed information of previously designated resistant QTLS (Supplementary Table 1) and drafted their genomic distributions using the released genome of hexaploid wheat (Fig. 2).

\section{Genetic loci controlling wheat resistance to Fusarium crown rot}

Since the causal agent of Fusarim head blight (FHB), Fusarium graminearum, can also induce the phenotype of Fusarium crown rot (Zhou et al. 2019; Akinsanmi et al. 2006), it is likely that FHB-resistant germplasm and genetic loci can be exploited to improve FCR resistance. For instance, the recently cloned FHB resistance gene $F h b 7$ encodes a glutathione S-transferase (GST) and provides broad resistance to Fusarium diseases, including FCR induced by $F$. pseudograminearum, by detoxifying trichothecenes through de-epoxidation (Wang et al. 2020). However, an earlier investigation of the same wheat genotypes found no significant correlation of resistant phenotype or genetic loci conferring resistance to FHB and FCR ( $\mathrm{Li}$ et al. 2010). A recent large-scale phenotyping of 205 Chinese wheat cultivars for resistance to both FHB and FCR also found no correlation in resistant phenotypes (Shi et al. 2020). Great efforts have also been made towards identification of FCR-resistant barley germplasm and genetic loci that control FCR resistance in barley (Liu and Ogbonnaya 2015). Since recent review papers have already summarized QTLs conferring FHB resistance and susceptibility in wheat in detail (Buerstmayr et al. 2020; Fabre et al. 2020), here we have mainly focused on studies reporting wheat resistance to FCR induced by F. pseudograminearum and F. culmorum. 
Genetic studies revealed a major FCR-resistant QTL on chromosome 3BL (Qcrs.cpi-3B). This resistant locus, Qcrs.cpi-3B, was identified in the wheat genotype "CSCR6" of the taxon Triticum spelta (Ma et al. 2010). In a wheat recombinant inbred line population of "Lang/CSCR6", a QTL on chromosome 4B derived from "Lang" explained the soil-free FCR resistance (Yang et al. 2010). Another significant QTL on chromosome 6B was identified as responsible for FCR resistance during an introgression process for durum wheat using "CSCR6" as the donor parent (Ma et al. 2012b). Near-isogenic lines for the Qcrs.cpi-3B locus have been developed for both genetic research and breeding practice (Ma et al. 2012a). Subsequent transcriptome and allele specificity analysis revealed differentially expressed genes associated with the Qcrs.cpi-3B locus (Ma et al. 2014). Fine mapping of this QTL shortened the genetic interval to $0.7 \mathrm{cM}$, containing 63 coding genes in the reference wheat genome (Zheng et al. 2015). Future map-based cloning and identification of the functional gene in this large-effect QTL may help elucidate the molecular bases of wheat resistance to FCR.

Other resistant QTLs have been identified using bi-parental populations. Early investigation discovered a resistant locus near the dwarfing gene Rht1 on chromosome 4B from the wheat cultivar "Kukri" (Wallwork et al. 2004). Inherited from the wheat line "W21MMT70" with partial resistance to FCR, two QTLs were mapped to chromosomes 2D and 5D (Bovill et al. 2006). A major QTL on chromosome 1DL (QCr.usq-1D1) and several minor QTLs were identified in wheat line "2-49 (Gluyas Early/Gala)" using SSR markers (Collard et al. 2006; Collard et al. 2005). FCR resistance screening of 32 wheat genotypes identified "2-49”, “Aso zairai 11", and "Ernie" as resistant sources. A QTL derived from "Ernie" was mapped to chromosome 3BL near markers wPt-1151 and wPt-1834 (Li et al. 2010). An Australian spring wheat cultivar "Sunco" showed partial resistance to FCR induced by F. pseudograminearum. Using bi-parental QTL mapping, a major QTL was identified on chromosome 3BL, between SSR markers Xgwm247 and Xgwm299 (Poole et al. 2012). These resistant sources of "W21MMT70", “2-49”, and "Sunto" were then used for QTL pyramiding (Bovill et al. 2010). Four FCR-resistant QTLs were discovered, and their resistant alleles were derived from the bread wheat commercial variety "EGA Wylie". Major QTLs on chromosomes 5DS and 2DL were consistently detected in all three populations and two minor QTLs were mapped to chromosome 4BS (Zheng et al. 2014). QTL mapping was also performed to find genetic loci 
controlling partial resistance to FCR in the four wheat germplasm "2-49", "Sunco", "IRN497", and "CPI133817". FCR resistance was evaluated in both seedlings and adult plants. Six QTLs among these resistant wheat genotypes were revealed (Martin et al. 2015).

A GWAS approach was used to screen 2,514 wheat genotypes for FCR resistance, and DArT and SSR markers identified two major QTLs on chromosome 3BL that explained 35\% and 49\% of the phenotypic variation (Liu et al. 2018). A set of 126 spring bread wheat lines from CIMMYT was phenotyped against FCR induced by F. culmorum and further genotyped using DArT markers, which resulted in the identification of three major QTLs on chromosomes 3B and 2D (Erginbasorakci et al. 2018). The use of GWAS for FCR resistance has greatly benefited from advanced high-throughput sequencing techniques and the released hexaploid wheat genome. A total of 234 Chinese wheat cultivars were evaluated for FCR resistance in four greenhouse experiments, with GWAS using a high-density 660K SNP assay. This revealed a major QTL on chromosome 6A, which was subsequently validated using a bi-parental population of "UC1110/PI610750" (Yang et al. 2019). The same team screened the FCR resistance of another 435 wheat introgression lines (generated by crossing of Yanzhan1 with other elite varieties) and performed GWAS using 660K SNP array. Most of the significant SNP associations were distributed on chromosome 4B and a gene encoding a dirigent protein (TaDIR-B1) was validated as a negative regulator of FCR resistance (Yang et al. 2021). A recent GWAS approach phenotyped 358 Chinese germplasm for FCR resistance, with less than 10\% exhibing a lower disease index. The wheat 55K SNP assay was applied for association analysis, resulting in detection of significant QTLs on chromosomes 1BS, 1DS, 5DS, 5DL, and 7BL (Jin et al. 2020). GWAS was also performed to evaluate FCR resistance of 161 wheat accessions under growth room and greenhouse conditions using F. culmorum as the pathogen. Using a 90K SNP array, a total of fifteen QTLs for FCR resistance were detected with one major QTL on chromosome 3BS near the FHB resistance Fhbl locus (Pariyar et al. 2020). A marker-assisted recurrent selection approach was next performed on two populations to pyramid minor FCRresistant QTLs. Using 9K SNP array, a total of 23 marker-trait associations were identified by GWAS (Rahman et al. 2020).

In Supplementary Table 2, we summarize wheat germplasm resistant to FCR induced by either F. pseudograminearum or F. culmorum. Identified QTLs controlling FCR resistance are 
also highlighted (Supplementary Table 2), with their genomic distributions annotated using the wheat genome database (Fig. 3).

\section{Genetic determinants of wheat resistance to sharp eyespot}

Wheat resistance to sharp eyespot is controlled by QTLs. However, additional efforts should focus on identification of resistant germplasm and genetic loci conferring resistance to this fungal disease. A recent large-scale screening of sharp eyespot resistant germplasm in Chinese wheat cultivars revealed no immune or highly resistant germplasm, and only $4 \%$ exhibiting moderate resistance to $R$. cerealis (Ren et al. 2020). Introgression of exogenous chromosome segments from wheat relatives might help generate novel resistant germplasms. For example, a wheat-rye $4 \mathrm{R}$ chromosome disomic addition line gained high resistance to sharp eyespot (An et al. 2019). Wheat cultivars "Luke" and "AQ24788-83" showed high resistance to $R$. cerealis. Subsequent genetic investigations revealed seven significant sharp eyespot resistant QTLs on chromosomes 1A, 2B, 3B, 4A, 5D, 6B, and 7B (Chen et al. 2013; Guo et al. 2017). Using 90 K SNP and SSR markers, five QTLs on chromosomes 2BS, 4BS, 5AL, and 5BS controlling resistance to $R$. cerealis were identified from the wheat cultivar "CI12633" (Wu et al. 2017). Three QTLs controlling resistance of wheat cultivars "Niavt14" and "Xuzhou25" to $R$. cerealis were mapped to chromosomes 2B and 7D (Jiang et al. 2016). A recent study using the same population of "Niavt14/Xuzhou25" and 55K SNPs revealed three novel stable QTLs on chromosomes 1D, 6D, and 7A (Liu et al. 2020).

In Supplementary Table 3, we summarize wheat germplasm resistant to $R$. cerealis. Reported QTLs controlling sharp eyespot resistance are highlighted (Supplementary Table 3), with their genomic distributions annotated using the wheat genome database (Fig. 4).

\section{Conclusion and future perspectives}

We have described three rot diseases that commonly infect the stem base of wheat plants (Fig. 1). These diseases are major threats to wheat productions in wheat-maize rotation areas with large-scale application of straw returning. Wheat breeding is the most efficient way to control these devastating fungal diseases. However, as summarized in this review (Supplementary

Tables 1, 2, and 3), there are few wheat germplasm with relative high resistance to $B$. 
sorokiniana, F. pseudograminearum, or R. cerealis. Large-scale screenings of resistant wheat germplasm are still urgently needed for effective wheat breeding applications. New germplasm resources including wheat relatives (e.g. introgression lines using Thinopyrum ponticum, Triticum spelta, and rye) may have great potential to improve wheat resistance to these root and crown rot fungal diseases.

Genetic improvement of wheat resistance to these diseases requires exploring novel QTLs that control resistance. There are several previously reported resistant QTLs (Supplementary Tables 1, 2, and 3) and their genomic distributions have been mapped based on the released wheat genome (Figs. 2,3, and 4). Some identified QTLs that confer resistance to B. sorokiniana are associated with loci responsible for wheat resistance to other foliar fungal diseases, such as Lr34/Yr18/Pm38, Lr46/Yr29, and Tsn1. Wheat leaves might restrain the infection of different foliar fungal diseases using similar molecular approaches mediated by resistant genes. Wheat germplasm with broad-spectrum resistant loci should be evaluated for potential resistance to spot blotch or common root rot induced by B. sorokiniana. Of QTLs that control resistance to Fusarium crown rot, ones that also have resistance to FHB may be more valuable, since the major causal agents of these diseases (F. pseudograminearum, F. culmorum, and $F$. graminearum) are very likely to co-exist in a cultivation environment. For genetic studies on QTLs controlling resistance to sharp eyespot, the large-scale screening of resistant wheat germplasm would greatly accelerate the identification of novel QTLs correlated with resistance to sharp eyespot. There is also an urgent need to employ GWAS technique to screen for more sharp eyespot resistant QTLs at the genome-wide level.

Constructing near-isogenic lines and using residual heterozygotes allow the use of fine mapping and further positional cloning for key gene/loci that control resistance. With advanced genomic and capture-sequencing techniques such as MutRenSeq, AgRenSeq, and Exome Capture, fast-cloning approaches might accelerate this time-consuming process (Steuernagel et al. 2016; Arora et al. 2019; Krasileva et al. 2017). Gene editing may also increase the rate of genetic improvement of wheat resistance to these fungal diseases (Wang et al. 2018). Both forward and reverse genetic studies will provide valuable targets for the application of CRISPRCas9 in wheat.

Efforts should also be made to convert traditional markers used previously to identify 
resistant QTLs (microsatellite, SSR, and DrAT) to SNP markers, as SNP markers may serve as valuable tools for high-throughput marker-assisted selection in wheat breeding. Progress in wheat genome research and increased availability of high-density SNP toolkits will facilitate the use of GWAS on collected wheat germplasm to more efficiently identify novel resistant sources and genetic loci.

\section{Acknowledgements}

The authors would like to thank Prof. Zaifeng Li from Hebei Agricultural University for discussion and input to this work.

\section{Declarations}

Authors' contributions: Conceptualization, X.W., Z.K., and W.Z; Data collection, J.S., J.Z., S.Z., M.L., S.P.; Original draft preparation, X.W.; Review and editing, S.C. and F.C.; Supervision, X.W., Z.K., and W.Z. All authors have read and agreed to the published version of the manuscript.

Funding: This work was supported by Open Project Program of National Key Laboratory of Wheat and Maize Crop Science, Provincial Supporting Program of Hebei for the Returned Oversea Scholars (C20190180), Open Project Program of State Key Laboratory of North China Crop Improvement and Regulation (NCCIR2020KF-4), National Key R\&D Program of China (2017YFD0300906), and Provincial Innovation Program of Hebei for Post-graduate Student (CXZZSS2021070).

Data availability: Not applicable.

Conflicts of Interest: The authors declare no conflict of interest.

Ethics approval and consent to participate: Not applicable.

Consent for publication: Not applicable.

\section{Reference}

Adhikari TB, Gurung S, Hansen JM, Jackson EW, Bonman JM (2012) Association mapping of quantitative trait loci in spring wheat landraces conferring resistance to bacterial leaf streak and spot blotch. Plant Genome 5 (1):1-16

Ahirwar RN, Mishra VK, Chand R, Budhlakoti N, Mishra DC, Kumar S, Singh S, Joshi AK (2018) Genome-wide association mapping of spot blotch resistance in wheat association mapping initiative (WAMI) panel of spring wheat (Triticum aestivum L.). PLoS ONE 13 (12):e0208196 
Akinsanmi OA, Backhouse D, Simpfendorfer S, Chakraborty S (2006) Genetic diversity of Australian Fusarium graminearum and F. pseudograminearum. Plant Pathology 55 (4):494-504

An D, Ma P, Zheng Q, Fu S, Li L, Han F, Han G, Wang J, Xu Y, Jin Y, Luo Q, Zhang X (2019) Development and molecular cytogenetic identification of a new wheat-rye $4 \mathrm{R}$ chromosome disomic addition line with resistances to powdery mildew, stripe rust and sharp eyespot. Theoretical and Applied Genetics 132 (1):257-272

Appels R, Eversole K, Stein N, Feuillet C, Keller B, Rogers J, Pozniak CJ, Choulet F, Distelfeld A, Poland J, Ronen G, Sharpe AG, Barad O, Baruch K, Keeble-Gagnère G, Mascher M, Ben-Zvi G, Josselin A-A, Himmelbach A, Balfourier F, Gutierrez-Gonzalez J, Hayden M, Koh C, Muehlbauer G, Pasam RK, Paux E, Rigault P, Tibbits J, Tiwari V, Spannagl M, Lang D, Gundlach H, Haberer G, Mayer KFX, Ormanbekova D, Prade V, Šimková H, Wicker T, Swarbreck D, Rimbert H, Felder M, Guilhot N, Kaithakottil G, Keilwagen J, Leroy P, Lux T, Twardziok S, Venturini L, Juhász A, Abrouk M, Fischer I, Uauy C, Borrill P, Ramirez-Gonzalez RH, Arnaud D, Chalabi S, Chalhoub B, Cory A, Datla R, Davey MW, Jacobs J, Robinson SJ, Steuernagel B, van Ex F, Wulff BBH, Benhamed M, Bendahmane A, Concia L, Latrasse D, Bartoš J, Bellec A, Berges H, Doležel J, Frenkel Z, Gill B, Korol A, Letellier T, Olsen O-A, Singh K, Valárik M, van der Vossen E, Vautrin S, Weining S, Fahima T, Glikson V, Raats D, Č́íhalíková J, Toegelová H, Vrána J, Sourdille P, Darrier B, Barabaschi D, Cattivelli L, Hernandez P, Galvez S, Budak H, Jones JDG, Witek K, Yu G, Small I, Melonek J, Zhou R, Belova T, Kanyuka K, King R, Nilsen K, Walkowiak S, Cuthbert R, Knox R, Wiebe K, Xiang D, Rohde A, Golds T, Č́źžková J, Akpinar BA, Biyiklioglu S, Gao L, N'Daiye A, Kubaláková M, Šafár J, Alfama F, Adam-Blondon A-F, Flores R, Guerche C, Loaec M, Quesneville H, Condie J, Ens J, Maclachlan R, Tan Y, Alberti A, Aury J-M, Barbe V, Couloux A, Cruaud C, Labadie K, Mangenot S, Wincker P, Kaur G, Luo M, Sehgal S, Chhuneja P, Gupta OP, Jindal S, Kaur P, Malik P, Sharma P, Yadav B, Singh NK, Khurana JP, Chaudhary C, Khurana P, Kumar V, Mahato A, Mathur S, Sevanthi A, Sharma N, Tomar RS, Holušová K, Plíhal O, Clark MD, Heavens D, Kettleborough G, Wright J, Balcárková B, Hu Y, Salina E, Ravin N, Skryabin K, Beletsky A, Kadnikov V, Mardanov A, Nesterov M, Rakitin A, Sergeeva E, Handa H, Kanamori H, Katagiri S, Kobayashi F, Nasuda S, Tanaka T, Wu J, Cattonaro F, Jiumeng M, Kugler K, Pfeifer M, Sandve S, Xun X, Zhan B, Batley J, Bayer PE, Edwards D, Hayashi S, Tulpová Z, Visendi P, Cui L, Du X, Feng K, Nie X, Tong W, Wang L (2018) Shifting the limits in wheat research and breeding using a fully annotated reference genome. Science 361 (6403):eaar7191

Arora S, Steuernagel B, Gaurav K, Chandramohan S, Long Y, Matny O, Johnson R, Enk J, Periyannan S, Singh N (2019) Resistance gene cloning from a wild crop relative by sequence capture and association genetics. Nature Biotechnology 37 (2):139-143

Ayana GT, Ali S, Sidhu JS, Hernandez JLG, Turnipseed B, Sehgal SK (2018) Genome-Wide Association Study for Spot Blotch Resistance in Hard Winter Wheat. Frontiers in Plant Science 9

Bainsla NK, Phuke RM, He X, Gupta V, Bishnoi SK, Sharma RK, Ataei N, Dreisigacker S, Juliana P, Singh PK (2020) Genome-wide association study for spot blotch resistance in Afghan wheat germplasm. Plant Pathology

Bovill WD, Horne M, Herde DJ, Davis M, Wildermuth GB, Sutherland MW (2010) Pyramiding QTL increases seedling resistance to crown rot (Fusarium pseudograminearum) of wheat (Triticum aestivum). Theoretical and Applied Genetics 121 (1):127-136

Bovill WD, Ma W, Ritter K, Collard BCY, Davis M, Wildermuth GB, Sutherland MW (2006) 
Identification of novel QTL for resistance to crown rot in the doubled haploid wheat population 'W21MMT70’×'Mendos'. Plant Breeding 125 (6):538-543

Buerstmayr M, Steiner B, Buerstmayr H (2020) Breeding for Fusarium head blight resistance in wheatprogress and challenges. Plant Breeding 139 (3):429-454

Burgess LW, Backhouse D, Summerell BA, Swan LJ (2001) Crown rot in wheat----Chapter 20. In: Summerell BA, Leslie JF, Backhouse D, Bryden WL, Burgess LW (eds) Fusarium-Paul E Nelson Memorial Symposium. APS Press, The American Phytopathological Society, St Paul,

Chen J, Li GH, Du ZY, Quan W, Zhang HY, Che MZ, Wang Z, Zhang ZJ (2013) Mapping of QTL conferring resistance to sharp eyespot (Rhizoctonia cerealis) in bread wheat at the adult plant growth stage. Theoretical and Applied Genetics 126 (11):2865-2878

Cohen SP, Leach JE (2020) High temperature-induced plant disease susceptibility: more than the sum of its parts. Current Opinion in Plant Biology 56:235-241

Collard BCY, Grams RA, Bovill WD, Percy CD, Jolley R, Lehmensiek A, Wildermuth G, Sutherland MW (2005) Development of molecular markers for crown rot resistance in wheat: mapping of QTLs for seedling resistance in a '2-49'×'Janz' population. Plant Breeding 124 (6):532-537. doi:10.1111/j.1439-0523.2005.01163.x

Collard BCY, Jolley R, Bovill WD, Grams RA, Wildermuth GB, Sutherland MW (2006) Confirmation of QTL mapping and marker validation for partial seedling resistance to crown rot in wheat line '2-49'. Crop Pasture Science 57 (9):967-973

Conner RL, Duczek LJ, Kozub GC, Kuzyk AD (1996) Influence of crop rotation on common root rot of wheat and barley. Canadian Journal of Plant Pathology 18 (3):247-254. doi:10.1080/07060669609500620

Erginbasorakci G, Sehgal D, Sohail Q, Ogbonnaya FC, Dreisigacker S, Pariyar SR, Dababat AA (2018) Identification of novel quantitative trait loci linked to crown rot resistance in spring wheat. International Journal of Molecular Sciences 19 (9):2666

Fabre F, Rocher F, Alouane T, Langin T, Bonhomme L (2020) Searching for FHB resistances in bread wheat: susceptibility at the crossroad. Frontiers in Plant Science 11 (731)

Guo Y, Du Z, Chen J, Zhang Z (2017) QTL mapping of wheat plant architectural characteristics and their genetic relationship with seven QTLs conferring resistance to sheath blight. PLoS ONE 12 (4): $\mathrm{e} 0174939$

Gupta PK, Chand R, Vasistha NK, Pandey SP, Kumar U, Mishra VK, Joshi AK (2018) Spot blotch disease of wheat: the current status of research on genetics and breeding. Plant Pathology 67 (3):508531

Gurung S, Mamidi S, Bonman JM, Xiong M, Brownguedira G, Adhikari TB (2014) Genome-wide association study reveals novel quantitative trait loci associated with resistance to multiple leaf spot diseases of spring wheat. PLoS ONE 9 (9):e108179

Hamada MS, Yin Y, Chen H, Ma Z (2011) The escalating threat of Rhizoctonia cerealis, the causal agent of sharp eyespot in wheat. Pest Managment Science 67 (11):1411-1419

He X, Dreisigacker S, Sansaloni C, Duveiller E, Singh RP, Singh PK (2020) QTL mapping for spot blotch resistance in two bi-parental mapping populations of bread wheat. Phytopathology 110 (12):1980-1987

Jamil M, Ali A, Gul A, Ghafoor A, Ibrahim AMH, Mujeeb-Kazi A (2018) Genome-wide association studies for spot blotch (Cochliobolus sativus) resistance in bread wheat using genotyping-bysequencing. Phytopathology 108 (11):1307-1314 
Jiang Y, Zhu F, Cai S, Wu J, Zhang Q (2016) Quantitative trait loci for resistance to Sharp Eyespot (Rhizoctonia cerealis) in recombinant inbred wheat lines from the cross Niavt $14 \times$ Xuzhou 25. Czech Journal of Genetic Plant Breeding 52 (4):139-144

Jin J, Duan S, Qi Y, Yan S, Li W, Li B, Xie C, Zhen W, Ma J (2020) Identification of a novel genomic region associated with resistance to Fusarium crown rot in wheat. Theoretical and Applied Genetics:1-11

Joshi AK, Kumar S, Chand R, Ortizferrara G (2004) Inheritance of resistance to spot blotch caused by Bipolaris sorokiniana in spring wheat. Plant Breeding 123 (3):213-219

Kazan K, Gardiner DM (2018) Fusarium Crown Rot Caused By Fusarium Psudograminearum In Cereal Crops: Recent Progress And Future Prospects. Molecular Plant Pathology 19 (7):1547-1562

Krasileva KV, Vasquez-Gross HA, Howell T, Bailey P, Paraiso F, Clissold L, Simmonds J, RamirezGonzalez RH, Wang X, Borrill P (2017) Uncovering hidden variation in polyploid wheat. Proceedings of the National Academy of Sciences 114 (6):E913-E921

Krattinger SG, Lagudah ES, Spielmeyer W, Singh RP, Huerta-Espino J, McFadden H, Bossolini E, Selter LL, Keller B (2009) A putative ABC transporter confers durable resistance to multiple fungal pathogens in wheat. Science 323 (5919):1360-1363

Kumar J, Schafer P, Huckelhoven R, Langen G, Baltruschat H, Stein E, Nagarajan S, Kogel K (2002) Bipolaris sorokiniana, a cereal pathogen of global concern: cytological and molecular approaches towards better control. Molecular Plant Pathology 3 (4):185-195

Kumar S, Roder MS, Singh RP, Kumar S, Chand R, Joshi AK, Kumar U (2016) Mapping of spot blotch disease resistance using NDVI as a substitute to visual observation in wheat (Triticum aestivum L.). Molecular Breeding 36 (7):95

Kumar S, Roder MS, Tripathi SB, Kumar S, Chand R, Joshi AK, Kumar U (2015) Mendelization and fine mapping of a bread wheat spot blotch disease resistance QTL. Molecular Breeding 35 (11):218

Kumar U, Joshi AK, Kumar S, Chand R, Roder MS (2009) Mapping of resistance to spot blotch disease caused by Bipolaris sorokiniana in spring wheat. Theoretical and Applied Genetics 118 (4):783792

Kumar U, Joshi AK, Kumar S, Chand R, Roder MS (2010) Quantitative trait loci for resistance to spot blotch caused by Bipolaris sorokiniana in wheat (T. aestivum L.) lines 'Ning 8201' and 'Chirya 3'. Molecular Breeding 26 (3):477-491

Kumar U, Kumar S, Tyagi K, Chand R, Joshi AK (2005) Microsatellite markers for resistance to spot blotch in spring wheat. Communications in Agricultural and Applied Biological Sciences 70 (3):59

Lemańczyk G, Kwaśna H (2013) Effects of sharp eyespot (Rhizoctonia cerealis) on yield and grain quality of winter wheat. Euroupean Journal of Plant Pathology 135 (1):187-200

Li H, Conner RL, Chen Q, Li H, Laroche A, Graf RJ, Kuzyk AD (2004) The transfer and characterization of resistance to common root rot from Thinopyrum ponticum to wheat. Genome 47 (1):215-223

Li HB, Xie GQ, Ma J, Liu GR, Wen SM, Ban T, Chakraborty S, Liu CJ (2010) Genetic relationships between resistances to Fusarium head blight and crown rot in bread wheat (Triticum aestivum L.). Theoretical and Applied Genetics 121 (5):941-950

Lillemo M, Joshi AK, Prasad R, Chand R, Singh RP (2013) QTL for spot blotch resistance in bread wheat line Saar co-locate to the biotrophic disease resistance loci Lr34 and Lr46. Theoretical and Applied Genetics 126 (3):711-719 
Liu C, Guo W, Zhang Q, Fu B, Yang Z, Sukumaran S, Cai J, Liu Y, Zhai W, Wu X (2020) Genetic Dissection of Adult Plant Resistance to Sharp Eyespot Using an Updated Genetic Map of Niavt14× Xuzhou25 Winter Wheat Recombinant Inbred Line Population. Plant Disease (ja)

Liu C, Ma J, Li HB, Liu YX, Liu GR, Wen SM, Zhou M, Yan G, Chakraborty S (2018) The homoeologous regions on long arms of group 3 chromosomes in wheat and barley harbour major crown rot resistance loci. Czech Journal of Genetic Plant Breeding 47:109-114

Liu C, Ogbonnaya FC (2015) Resistance to Fusarium crown rot in wheat and barley: a review. Plant Breeding 134 (4):365-372

Lu P, Liang Y, Li DF, Wang Z, Li W, Wang G, Wang Y, Zhou S, Wu Q, Xie J (2016) Fine genetic mapping of spot blotch resistance gene Sb3 in wheat (Triticum aestivum). Theoretical and Applied Genetics 129 (3):577-589

Ma J, Li HB, Zhang C, Yang XM, Liu Y, Yan G, Liu C (2010) Identification and validation of a major QTL conferring crown rot resistance in hexaploid wheat. Theoretical and Applied Genetics 120 (6):1119-1128

Ma J, Stiller J, Zhao Q, Feng Q, Cavanagh CR, Wang P, Gardiner DM, Choulet F, Feuillet C, Zheng Y (2014) Transcriptome and allele specificity associated with a 3BL locus for Fusarium crown rot resistance in bread wheat. PLoS ONE 9 (11):e113309

Ma J, Yan G, Liu C (2012a) Development of near-isogenic lines for a major QTL on 3BL conferring Fusarium crown rot resistance in hexaploid wheat. Euphytica 183 (2):147-152

Ma J, Zhang CY, Liu YX, Yan GJ, Liu CJ (2012b) Enhancing Fusarium crown rot resistance of durum wheat by introgressing chromosome segments from hexaploid wheat. Euphytica 186 (1):67-73

Martin A, Bovill WD, Percy CD, Herde DJ, Fletcher S, Kelly A, Neate SM, Sutherland MW (2015) Markers for seedling and adult plant crown rot resistance in four partially resistant bread wheat sources. Theoretical and Applied Genetics 128 (3):377-385

McBeath JH, McBeath J (2010) Plant diseases, pests and food security. In: Environmental Change and Food Security in China, vol 35. Springer, Dordrecht, Advances in Global Change Research, pp 117-156

Monds RD, Cromey MG, Lauren DR, Menna MED, Marshall JW (2005) Fusarium graminearum, F. cortaderiae and F. pseudograminearum in New Zealand: molecular phylogenetic analysis, mycotoxin chemotypes and co-existence of species. Fungal Biology 109 (4):410-420

Obanor F, Chakraborty S (2014) Aetiology and toxigenicity of Fusarium graminearum and F. pseudograminearum causing crown rot and head blight in Australia under natural and artificial infection. Plant Pathology 63 (6):1218-1229

Pariyar SR, Erginbasorakci G, Dadshani S, Chijioke OB, Leon J, Dababat AA, Grundler FMW (2020) Dissecting the genetic complexity of Fusarium crown rot resistance in wheat. Scientific Report $10(1): 1-13$

Peralta AL, Sun Y, McDaniel MD, Lennon JT (2018) Crop rotational diversity increases disease suppressive capacity of soil microbiomes. Ecosphere 9 (5):e02235. doi:10.1002/ecs2.2235

Poole GJ, Smiley RW, Paulitz TC, Walker C, Carter AH, See DR, Garlandcampbell K (2012) Identification of quantitative trait loci (QTL) for resistance to Fusarium crown rot (Fusarium pseudograminearum) in multiple assay environments in the Pacific Northwestern US. Theoretical and Applied Genetics 125 (1):91-107

Rahman M, Davies P, Bansal U, Pasam R, Hayden M, Trethowan R (2020) Marker-assisted recurrent selection improves the crown rot resistance of bread wheat. Molecular Breeding 40 (3):28 
Ren Y, Yu P-B, Wang Y, Hou W-X, Yang X, Fan J-L, Wu X-H, Lv X-L, Zhang N, Zhao L (2020) Development of a Rapid Approach for Detecting Sharp Eyespot Resistance in Seedling-Stage Wheat and Its Application in Chinese Wheat Cultivars. Plant Disease:PDIS-12-19-2718-RE

Sharma RC, Duveiller E (2007) Advancement toward new spot blotch resistant wheats in South Asia. Crop Science 47 (3):961-968

Sharma RC, Duveiller E, Jacquemin JM (2007) Microsatellite Markers Associated with Spot Blotch Resistance in Spring Wheat. Journal of Phytopathology 155 (5):316-319

Shi S, Zhao J, Pu L, Sun D, Han D, Li C, Feng X, Fan D, Hu X (2020) Identification of new sources of resistance to crown rot and Fusarium head blight in Wheat. Plant Disease 104 (7):1979-1985

Singh PK, He X, Sansaloni C, Juliana P, Dreisigacker S, Duveiller E, Kumar U, Joshi AK, Singh RP (2018) Resistance to Spot Blotch in Two Mapping Populations of Common Wheat Is Controlled by Multiple QTL of Minor Effects. International Journal of Molecular Sciences 19 (12):4054

Singh V, Singh G, Chaudhury A, Ojha A, Tyagi BS, Chowdhary AK, Sheoran S (2016) Phenotyping at hot spots and tagging of QTLs conferring spot blotch resistance in bread wheat. Molecular Biology Reports 43 (11):1293-1303

Smiley RW, Gourlie JA, Easley SA, Patterson L (2005) Pathogenicity of Fungi Associated with the Wheat Crown Rot Complex in Oregon and Washington. Plant Disease 89 (9):949-957

Steuernagel B, Periyannan SK, Hernández-Pinzón I, Witek K, Rouse MN, Yu G, Hatta A, Ayliffe M, Bariana H, Jones JD (2016) Rapid cloning of disease-resistance genes in plants using mutagenesis and sequence capture. Nature Biotechnology 34 (6):652-655

Sun C, Dong Z, Zhao L, Ren Y, Zhang N, Chen F (2020) The Wheat 660K SNP array demonstrates great potential for marker-assisted selection in polyploid wheat. Plant Biotechnology Journal

Tembo B, Sibiya J, Tongoona P, Tembo L (2017) Validation of microsatellite molecular markers linked with resistance to Bipolaris sorokiniana in wheat (Triticum aestivum L.). The Journal of Agricultural Science 155 (7):1061-1068

Tomar V, Singh RP, Poland J, Singh D, Joshi AK, Singh PK, Bhati PK, Kumar S, Rahman M, Dhillon GS, Tiwari BS, Kumar U (2020) Genome-wide association study and genomic prediction of spot blotch disease in wheat (Triticum aestivum L.) using genotyping by sequencing. Research Square Preprint

Wallwork H, Butt M, Cheong J, Williams KJ (2004) Resistance to crown rot in wheat identified through an improved method for screening adult plants. Australasian Plant Pathology 33 (1):1-7

Wang H, Sun S, Ge W, Zhao L, Hou B, Wang K, Lyu Z, Chen L, Xu S, Guo J, Li M, Su P, Li X, Wang G, Bo C, Fang X, Zhuang W, Cheng X, Wu J, Dong L, Chen W, Li W, Xiao G, Zhao J, Hao Y, Xu Y, Gao Y, Liu W, Liu Y, Yin H, Li J, Li X, Zhao Y, Wang X, Ni F, Ma X, Li A, Xu SS, Bai G, Nevo E, Gao C, Ohm H, Kong L (2020) Horizontal gene transfer of Fhb7 from fungus underlies Fusarium head blight resistance in wheat. Science 368 (6493):eaba5435

Wang J, Wang X, Xu M, Feng G, Zhang W, Yang X, Huang S (2015) Contributions of wheat and maize residues to soil organic carbon under long-term rotation in north China. Scientific Report 5 (1):11409. doi:10.1038/srep11409

Wang M, Wang S, Liang Z, Shi W, Gao C, Xia G (2018) From genetic stock to genome editing: gene exploitation in wheat. Trends in Biotechnology 36 (2):160-172

William M, Singh RP, Huertaespino J, Islas SO, Hoisington DA (2003) Molecular marker mapping of leaf rust resistance gene $L r 46$ and its association with stripe rust resistance gene $\operatorname{Yr} 29$ in wheat. Phytopathology 93 (2):153-159 
Wu X, Cheng K, Zhao R, Zang S, Bie T, Jiang Z, Wu R, Gao D, Zhang B (2017) Quantitative trait loci responsible for sharp eyespot resistance in common wheat CI12633. Scientific Report 7 (1):17

Yang X, Ma J, Li H, Ma H, Yao J, Liu C (2010) Different genes can be responsible for crown rot resistance at different developmental stages of wheat and barley. Euroupean Journal of Plant Pathology 128 (4):495-502

Yang X, Pan Y, Singh PK, He X, Ren Y, Zhao L, Zhang N, Cheng S, Chen F (2019) Investigation and genome-wide association study for Fusarium crown rot resistance in Chinese common wheat. BMC Plant Biology 19 (1):153

Yang X, Zhong S, Zhang Q, Ren Y, Sun C, Chen F (2021) A loss-of-function of the dirigent gene TaDIRB1 improves resistance to Fusarium crown rot in wheat. Plant Biotechnology Journal

Zhang P, Guo G, Wu Q, Chen Y, Xie J, Lu P, Li B, Dong L, Li M, Wang R, Yuan C, Zhang H, Zhu K, Li W, Liu Z (2020) Identification and fine mapping of spot blotch (Bipolaris sorokiniana) resistance gene $S b 4$ in wheat. Theoretical and Applied Genetics 133 (4)

Zhao R, Chen X, Zhang F, Zhang H, Schroder JL, Romheld V (2006) Fertilization and Nitrogen Balance in a Wheat-Maize Rotation System in North China. Agronomy Journal 98 (4):938-945

Zheng Z, Kilian A, Yan G, Liu C (2014) QTL conferring fusarium crown rot resistance in the elite bread wheat variety EGA Wylie. PLoS ONE 9 (4):e96011

Zheng Z, Ma J, Stiller J, Zhao Q, Feng Q, Choulet F, Feuillet C, Zheng Y, Wei Y, Han B (2015) Fine mapping of a large-effect QTL conferring Fusarium crown rot resistance on the long arm of chromosome 3B in hexaploid wheat. BMC Genomics 16 (1):850-850

Zhou H, He X, Wang S, Ma Q, Sun B, Ding S, Chen L, Zhang M, Li H (2019) Diversity of the Fusarium pathogens associated with crown rot in the Huanghuai wheat-growing region of China. Environmental Microbiology 21 (8):2740-2754

Zhu Z, Bonnett D, Ellis M, Singh PK, Heslot N, Dreisigacker S, Gao C, Mujeebkazi A (2014) Mapping resistance to spot blotch in a CIMMYT synthetic-derived bread wheat. Molecular Breeding 34 (3):1215-1228 


\section{Figure legends}

Fig. 1 Pathogenic profiles of Bipolaris sorokiniana, Fusarium pseudograminearum, and Rhizoctonia cerealis. a B. sorokiniana was cultivated on potato dextrose agar (PDA) medium and spores were directly collected. b Common root rot and spot blotch caused by B. sorokiniana. Infected wheat plants were easily pulled out, the stem base and root system felt wet, and black and brown striped spots can be observed in both the stem base and lower leaves. c $F$. pseudograminearum cultivated on PDA medium. Spores of $F$. pseudograminearum can be induced on carboxymethyl cellulose sodium (CMC) medium. d Fusarium crown rot caused by F. pseudograminearum. The stem base of infected wheat plants became dry and fragile, and was easily broken apart. Additionally, dark and red brown rot can be observed in the stem base. $\mathrm{e}$. cerealis was cultivated on PDA medium. f Sharp eyespot caused by $R$. cerealis. The typical lesions on wheat stem are elliptical or exhibit an "eye" shape with sharply dark brown borders. Scale bar $=20 \mu \mathrm{m}$.

Fig. 2 Genetics of resistance to common root rot (spot blotch) in wheat. Molecular markers, SNPs, and genes associated with common root rot or spot blotch resistant QTLs were collected from previous publications and searched against the JBrowse-1.12.3-release of the common wheat "Chinese Spring" genome available from the "Triticeae Multi-omics Center (http://202.194.139.32/)". Physical positions (numbers indicated on the left side of each chromosome) were used to generate a distribution map of all the collected QTLs using Mapchart v2.32 software. QTLs with major effect or linked with designated genes are highlighted in red. Detailed information for these QTLs can be found in

\section{Supplementary Table 1.}

Fig. 3 Genetic loci controlling wheat resistance to Fusarium crown rot. Molecular markers, SNPs, and genes associated with FCR-resistant QTLs were collected from previous publications and searched against the JBrowse-1.12.3-release of the common wheat "Chinese Spring" genome available from the "Triticeae Multi-omics Center (http://202.194.139.32/)". Physical positions (numbers indicated on the left side of each chromosome) were used to generate a distribution map of all the collected QTLs using Mapchart v2.32 software. QTLs with major effect or linked with designated genes are highlighted in red. Detailed information for these QTLs can be found in Supplementary

Table 2.

Fig. 4 Identified QTLs controlling wheat resistance to sharp eyespot. Molecular markers associated with Rc-resistant QTLs were collected from previous publications and searched 
against the JBrowse-1.12.3-release of the common wheat "Chinese Spring" genome available from the "Triticeae Multi-omics Center (http://202.194.139.32/)". Physical positions (numbers indicated on the left side of each chromosome) were used to generate a distribution map of all the collected QTLs using Mapchart v2.32 software. Detailed information for these QTLs can be found in Supplementary Table 3. 
a

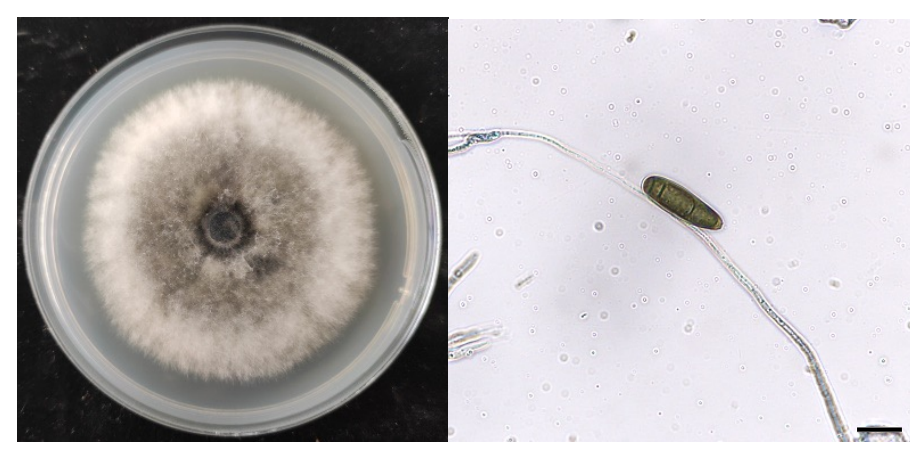

Bipolaris sorokiniana

c

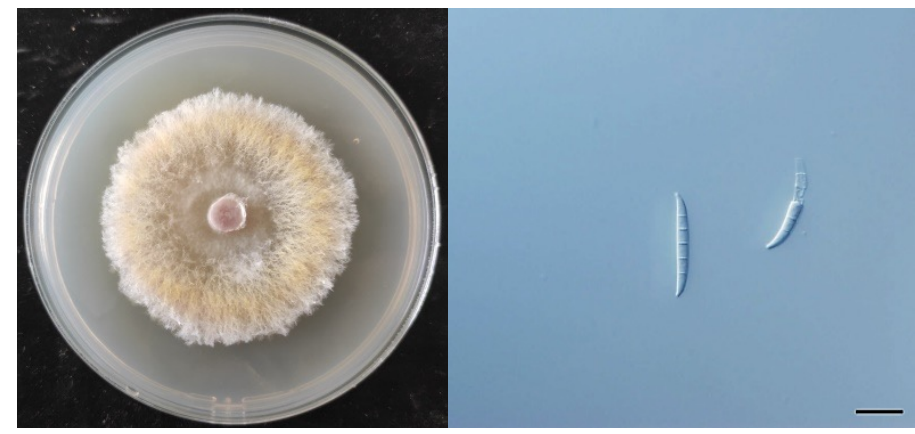

Fusarium pseudograminearum

e

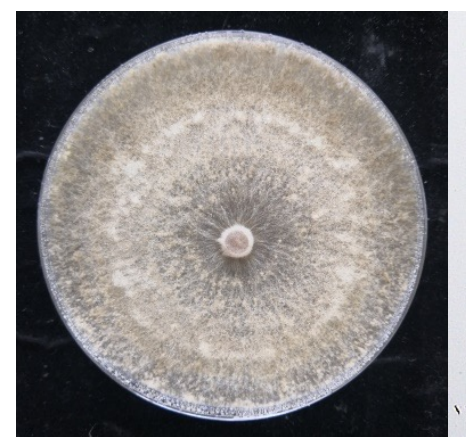

Rhizoctonia cerealis b

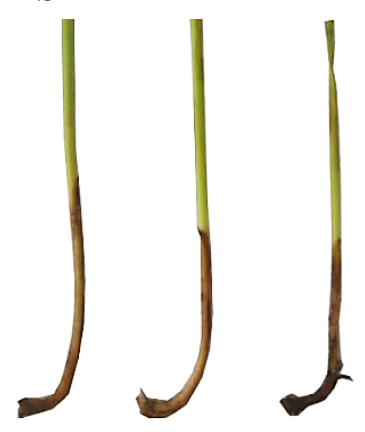

Common Root Rot d

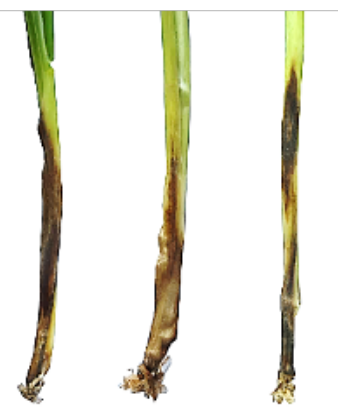

Fusarium Crown Rot
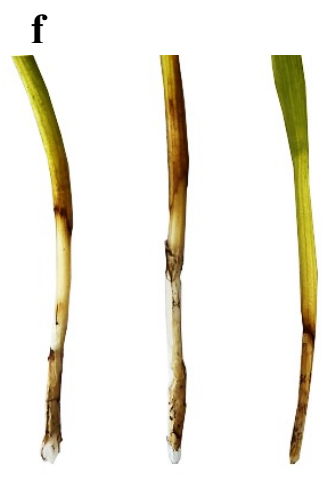

Sharp Eyespot

Fig. 1 


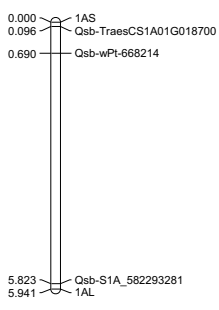

3A

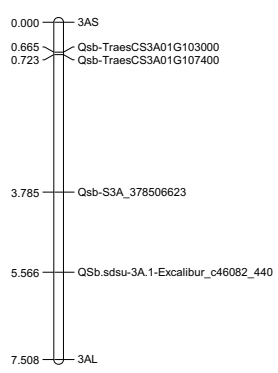

$5 A$

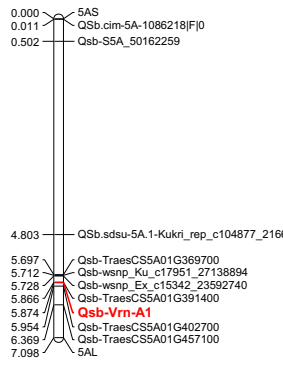

$7 \mathrm{~A}$

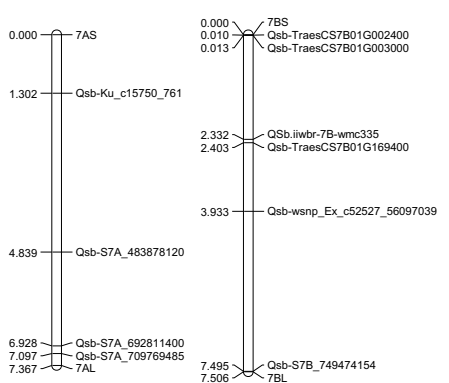

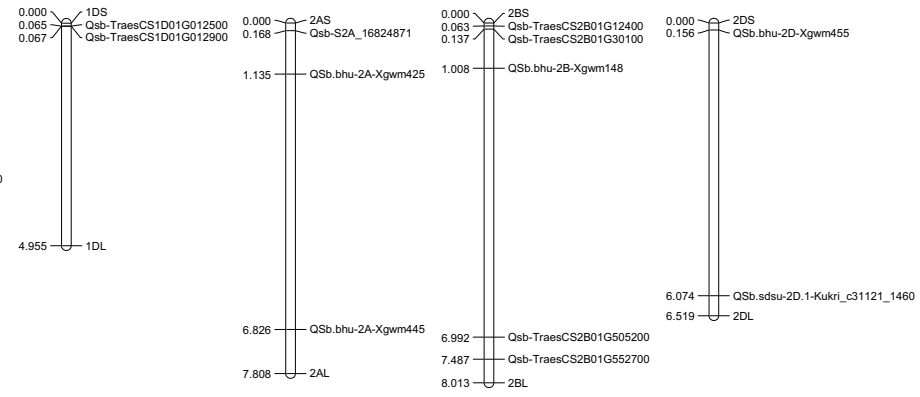

3D

4A

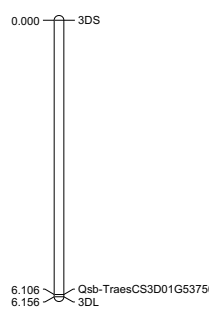

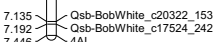
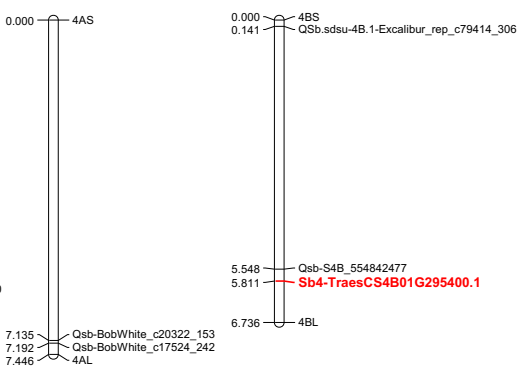

$6 B$

6D

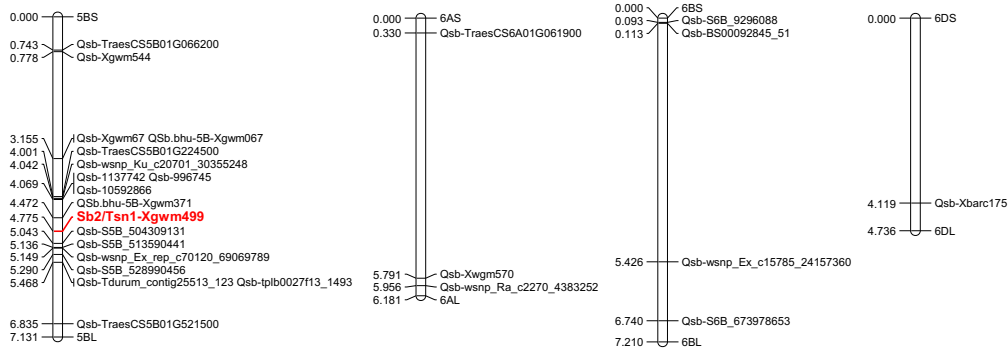

7D

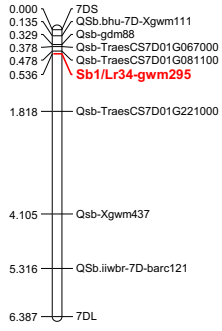

Fig. 2 


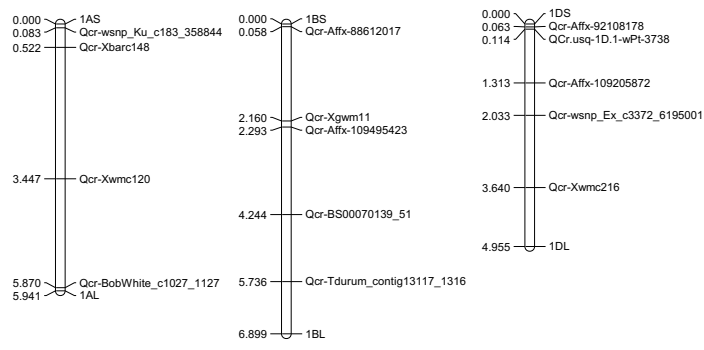

3 A

3B

3D
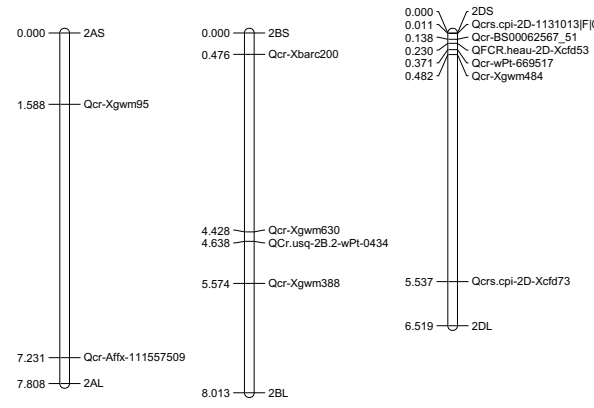

4 A

4B

5A
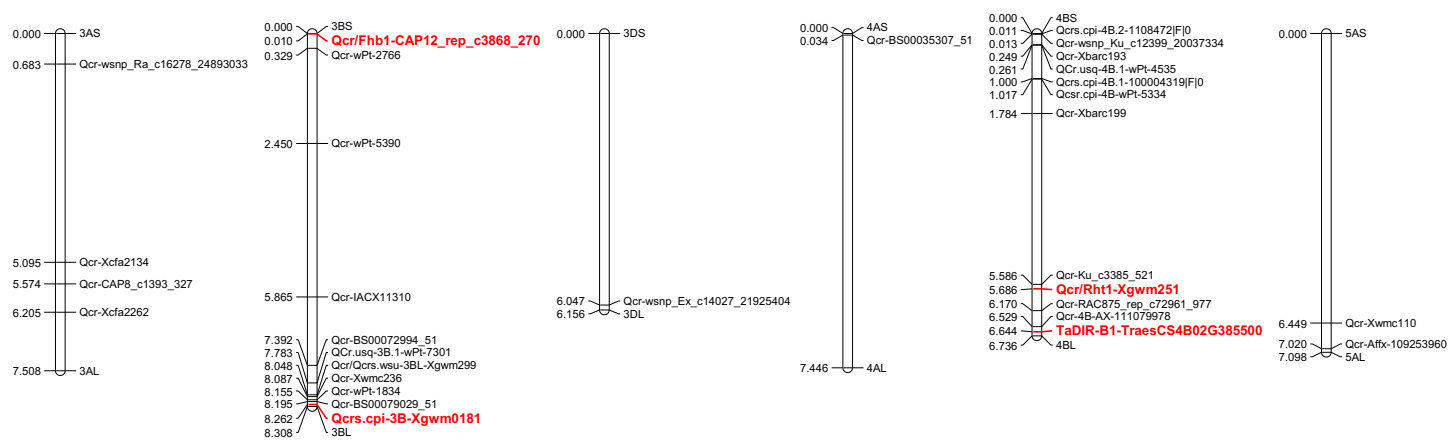

5B

5D

$6 A$

6B

6D

7A

7B

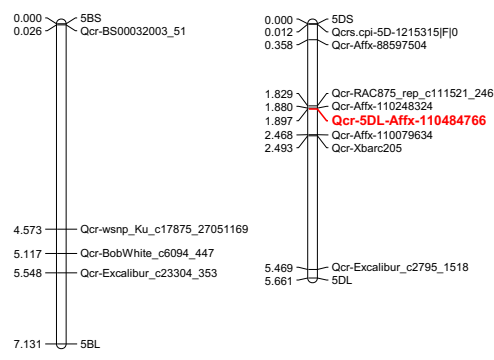

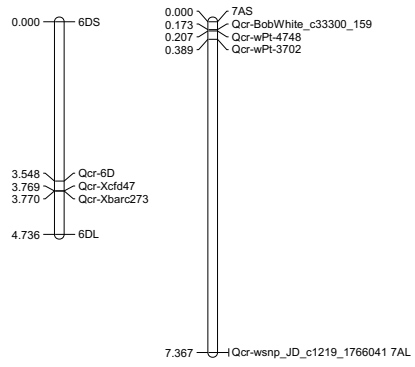

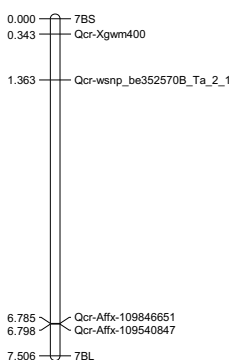

Fig. 3 

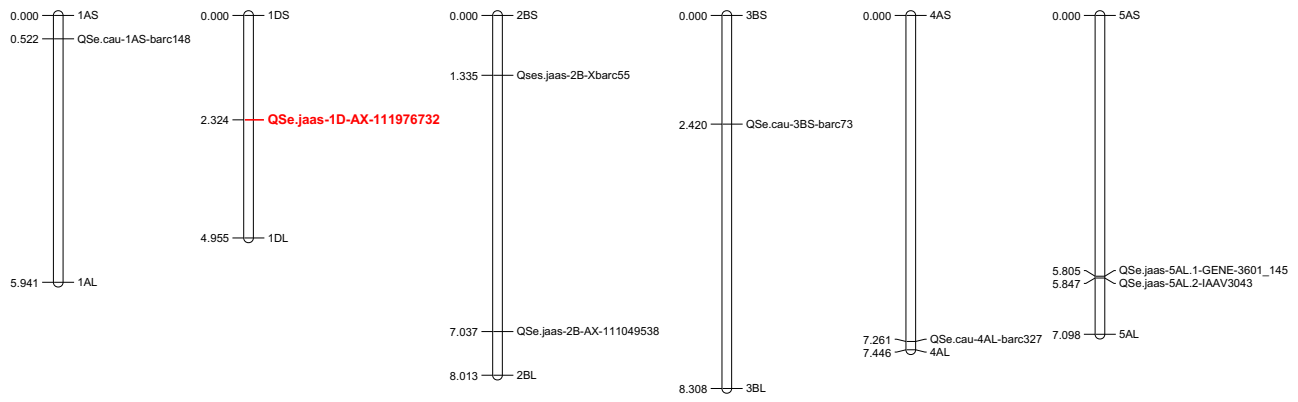

5B
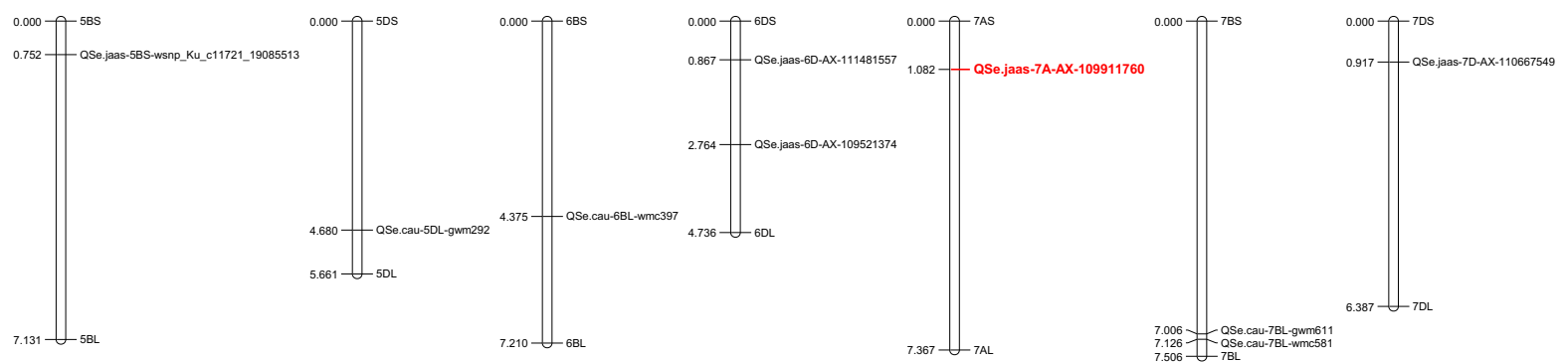

Fig. 4 
Supplementary Table 1. Genetics of resistance to common root rot (spot blotch) in wheat.

\begin{tabular}{|c|c|c|c|}
\hline QTL name & Associated markers or SNPs & Resistant wheat germplasms & Reference \\
\hline Sb1/Lr34* & 7DS: Xgwm295, csLV34 & & \\
\hline $\begin{array}{c}Q s b \\
\text { Osb/Lr46/Yr29* }\end{array}$ & $\begin{array}{l}\text { 7DS: } w P t-7654, \boldsymbol{g d m} \boldsymbol{8 \boldsymbol { 8 }} \\
\text { 1BL: } \boldsymbol{w m c} 71 \mathbf{9} \text {, hbe248, ncwl-V }\end{array}$ & Saar & (Lillemo et al. 2013) \\
\hline$S b 2 / T s n 1 *$ & 5BL: Xgwm 499, Xgwm639, Xgwm 1043 & YS116, CASCABEL & $\begin{array}{l}\text { (Kumar et al. 2015; } \\
\text { Kumar et al. 2016; He et } \\
\text { al. ; Bainsla et al.) }\end{array}$ \\
\hline$S b 3^{*}$ & 3BS: Xbarc147, XWGGC3957, XWGGC4320 & $621-7-1$ & (Lu et al. 2016) \\
\hline$S b 4 *$ & 4B: TraesCS4B01G295400.1 & Zhongyu1211, GY17 & (Zhang et al. 2020) \\
\hline$Q s b$ & $\begin{array}{l}\text { 5B: } \boldsymbol{X g} \boldsymbol{w} \boldsymbol{m} 544 \\
\text { 7D: } \boldsymbol{X g} \boldsymbol{w} \boldsymbol{m} \mathbf{m 3 7}\end{array}$ & Yangmai 6 & (Kumar et al. 2005) \\
\hline$Q s b$ & 5B: Xgwm67 & G162 & (Sharma et al. 2007) \\
\hline QSb.bhu-2A & 2AL: Xbarc353, Xgwm 445 & \multirow{4}{*}{ Yangmai 6} & \multirow{4}{*}{ (Kumar et al. 2009) } \\
\hline QSb.bhu-2B & 2BS: Xgwm 148, Xgwm 374 & & \\
\hline QSb.bhu- $5 B$ & 5BL: Xgwm067, Xgwm 371 & & \\
\hline QSb.bhu- $6 D$ & 6DL: Xbarc 175, Xgwm732 & & \\
\hline QSb.bhu-2A & 2AS: Xgwm 425, Xbarc159 & \multirow{4}{*}{ Ning 8201} & \multirow{4}{*}{ (Kumar et al. 2010) } \\
\hline QSb.bhu-2B & 2BS: $\boldsymbol{X g w m ~ 1 4 8 , ~ X b a r c ~} 91$ & & \\
\hline QSb.bhu-5B & 5BL: Xgwm 067, Xgwm 213 & & \\
\hline QSb.bhu-7D & 7DS:Xgwm 111, Xgwm 1168 & & \\
\hline QSb.bhu-2B & 2BS: Xgwm 148, Xgwm129 & \multirow{5}{*}{ Chirya 3} & \multirow{5}{*}{ (Kumar et al. 2010) } \\
\hline QSb.bhu-2D & 2DS: Xgwm 455, Хgwm 815 & & \\
\hline QSb.bhu-3B & 3BS: Xgwm533, Xgwm 1037 & & \\
\hline QSb.bhu-7B & 7BS: Xgwm263, Xgwm255 & & \\
\hline QSb.bhu-7D & 7DS: Xgwm 111, Xswm008 & & \\
\hline QSb.cim- $1 B$ & 1B:Xwmc128, Xgwm374 & \multirow{3}{*}{ SYN1, Mayoor, Tksn1081/Ae. squarrosa (222) } & \multirow{3}{*}{ (Zhu et al. 2014) } \\
\hline QSb.cim-3B & 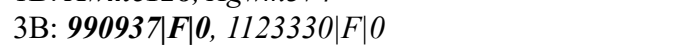 & & \\
\hline QSb.cim- $5 A$ & 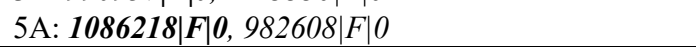 & & \\
\hline $\begin{array}{l}\text { QSb.iiwbr-7B } \\
\text { QSb.iiwbr-7D }\end{array}$ & $\begin{array}{l}\text { 7BL: } w m c 758, \boldsymbol{w m c} 335 \\
\text { 7DL: wmc653, barc121 }\end{array}$ & BH 1146 & (Singh et al. 2016) \\
\hline$Q s b / V r n-A 1^{*}$ & 5AL: $\boldsymbol{V} \boldsymbol{r} \boldsymbol{n}-\boldsymbol{A l}$ & BARTAI, WUYA, CASCABEL, KATH & $\begin{array}{l}\text { (Singh et al. 2018; He et } \\
\text { al. ; Bainsla et al.) }\end{array}$ \\
\hline$Q s b$ & $\begin{array}{l}\text { 1A: } w P t-730148, \boldsymbol{w P t - 6 6 8 2 1 4} \\
\text { 3B: } \boldsymbol{w P t - 1 1 5 9 ,} \boldsymbol{w P t - 5 7 6 9} \\
\text { 7B: } w P t-2838\end{array}$ & $\begin{array}{l}\text { Chirya 7, Forma Vinda de Varmland (PI 192569), } \\
\text { IWA8600074 (PI 623098), Trigo (PI 477878), Soprimo (PI } \\
\text { 479890), CI } 10112 \text { (PI 78814), Florentino (PI 565255), AW }\end{array}$ & (Adhikari et al. 2012) \\
\hline
\end{tabular}


(PI 429667)

\begin{tabular}{|c|c|c|c|}
\hline & & & \\
\hline$Q s b$ & 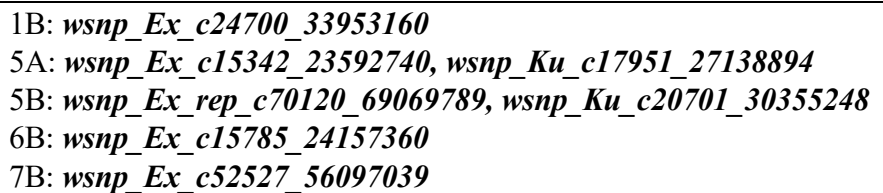 & $\begin{array}{l}\text { PI25989, PI384237, PI384239, PI479802, PI479890, } \\
\text { PI576639, PI245377, PI366685, PI481715, PI624517, } \\
\text { PI481574, PI91235, PI350795, PI565213 }\end{array}$ & (Gurung et al. 2014) \\
\hline$Q s b$ & $\begin{array}{l}\text { 5B: Xgwm544 } \\
\text { 6A: Xwgm570 } \\
\text { 7D: Xgwm437 }\end{array}$ & 19HRWSN6, 30SAWSN5 & (Tembo et al. 2017) \\
\hline $\begin{array}{l}\text { QSb.sdsu-2D.1 } \\
\text { QSb.sdsu-3A.1 } \\
\text { QSb.sdsu-4A.1 } \\
\text { QSb.sdsu-4B.1 } \\
\text { QSb.sdsu-5A.1 } \\
\text { QSb.sdsu-7B.1 }\end{array}$ & $\begin{array}{l}\text { 2D: Kukri_c31121_1460 } \\
\text { 3A: } \text { Excalibur_c46082_440 } \\
\text { 4A: IWA8475 } \\
\text { 4B: Excalibur_rep_c79414_306 } \\
\text { 5A: Kukri_rep_c104877_2166 } \\
\text { 7B: TA005844-0160 }\end{array}$ & $\begin{array}{l}\text { Duster, Colt, Custer, Intrada, MT0495, NE99495, OK04525, } \\
\text { OK05122, OK05723W, Venango }\end{array}$ & (Ayana et al. 2018) \\
\hline$Q s b$ & 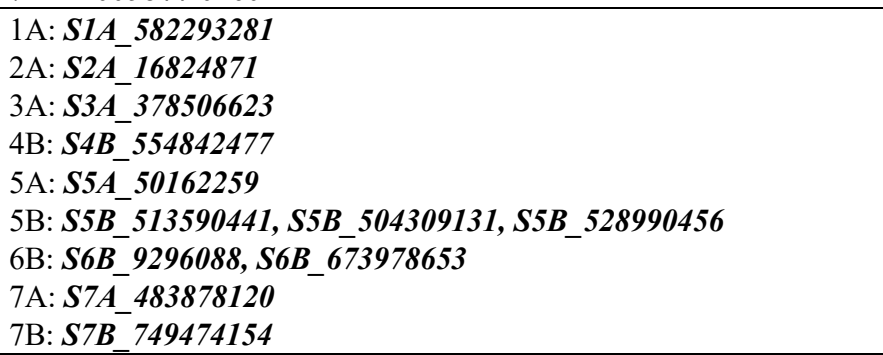 & $\begin{array}{c}\text { Chirya.3, Aust-53, Pak-13, SB12-6704, 7HTWSN-4516, } \\
\text { 7HTWSN-4513, Aust-8, SB12-6703, Aust-66, SB12-6720, } \\
\text { Aust-12, 7HTWSN-4522, 7HTWSN-4526, 7HTWSN-4412, } \\
\text { 7HTWSN-4405, 7HTWSN-4517, H.Sat-8, Aust-59, Aust-29, } \\
\text { 7HTWSN-4406, 7HTWSN-4510 }\end{array}$ & (Jamil et al. 2018) \\
\hline$Q s b$ & $\begin{array}{l}\text { 1B: BobWhite_c17559_105 } \\
\text { 4A: BobWhite_c20322_153, BobWhite_c17524_242 } \\
\text { 5B: Tdurum_contig25513_123, tplb0027f13_1493 } \\
\text { 6A: wsnp_Ra_c2270_4383252 } \\
\text { 6B: BS00092845_51 } \\
\text { 7A: Ku_c15750_761 }\end{array}$ & N. A. & (Ahirwar et al. 2018) \\
\hline$Q s b$ & $\begin{array}{l}\text { 1B: TraesCS1B01G416200 } \\
\text { 5A: TraesCS5A01G391400, TraesCS5A01G369700 }\end{array}$ & $\begin{array}{c}\text { 0KATIA, DE9, OK82282//BOW/NKT/3/F4105, } \\
\text { PSN/BOW//ROEK/3/MILAN, KAUZ 2*/OPATA//KAUZ, } \\
\text { ALTAR84/AE.SQ//2*, CNDO/R143//ENTE/MEXI-2/3/.., } \\
\text { PAMIR-94 x, NING9415, RENESANSA, VORONA/CUPE }\end{array}$ & (Bainsla et al.) \\
\hline$Q s b$ & $\begin{array}{l}\text { 1A: TraesCS1A01G018700 } \\
\text { 1B: TraesCS1B01G424000, TraesCS1B01G423900 }\end{array}$ & N. A. & (Tomar et al. 2020) \\
\hline
\end{tabular}


1D: TraesCS1D01G012500, TraesCS1D01G012900

2B: TraesCS2B01G505200, TraesCS2B01G552700, TraesCS2B01G12400,

TraesCS2B01G30100

3A: TraesCS3A01G107400, TraesCS3A01G103000

3B: TraesCS3B01G520100

3D: TraesCS3D01G537500

5A: TraesCS5A01G402700, TraesCS5A01G457100

5B: TraesCS5B01G066200, TraesCS5B01G224500,

TraesCS5B01G521500

6A: TraesCS6A01G061900

7A: TraesCS7A01G504700, TraesCS7A01G530700

7B: TraesCS7B01G002400, TraesCS7B01G003000,

TraesCS7B01G169400

7D: TraesCS7D01G067000, TraesCS7D01G081100,

TraesCS7D01G221000

Genomic distribution of all these summarized resistant loci were drafted using associated markers and SNPs (bold labeled) that can be found in "Chinese

Spring" wheat genome database. QTLs with major effect or linked with designated genes were labeled with asterisk (*) and highlighted in Fig. 2. 
Supplementary Table 2. Genetic loci controlling wheat resistance to Fusarium crown rot.

\begin{tabular}{|c|c|c|c|}
\hline QTL name & Associated markers or SNPs & Resistant wheat germplasms & Reference \\
\hline Qcrs.cpi-3B* & 3BL: Xgwm0181, wPt-10505, wPt-2277 & \multirow{4}{*}{ CSCR6 (T. spelta), Lang, Kennedy } & \multirow{4}{*}{$\begin{array}{l}\text { (Ma et al. 2010; Ma et al. 2012a; Ma et al. 2014; } \\
\text { Zheng et al. 2015; Ma et al. 2012b; Yang et al. 2010) }\end{array}$} \\
\hline Qcsr.cpi-4B & 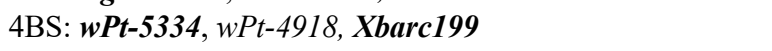 & & \\
\hline Qcr & 5A: Xwmc110 & & \\
\hline Qcr & 6B: Xwmc494, Xgwm193, Xwmc397, Xbarc198, Xbarc178 & & \\
\hline \multirow{3}{*}{ Qcr } & 2BS: Xgdm086, Xbarc200 & & \multirow{8}{*}{$\begin{array}{c}\text { (Wallwork et al. 2004; Collard et al. 2006; Collard et } \\
\text { al. 2005) }\end{array}$} \\
\hline & 2D: Xwmc018, Xwmc190 & W21MMT70, Mendos & \\
\hline & 5D: Xbarc205, barc143 & & \\
\hline$Q c r$ & 1AL: Xwmc120, Xwmc312 & \multirow{5}{*}{ Kukri, 2-49 (Gluyas Early/Gala), Janz } & \\
\hline QCr.usq-1D.1 & 1DS: Xcfd19 & & \\
\hline QCr.usq-2B.1 & 2BS: Xbarc349.1, Xgwm 388 & & \\
\hline Qcr/Rht1* & 4BL: Xgwm165, Xgwm251 & & \\
\hline Qcr & 7BS: Xgwm 400, Xwmc476 & & \\
\hline QCr.usq-1D.1 & 1DS: $\boldsymbol{w P t - 3 7 3 8 , ~ X c f d 1 9 , ~ w P t - 9 3 8 0 ~}$ & \multirow{5}{*}{ 2-49, W21MMT70, Sunto } & \multirow{5}{*}{ (Bovill et al. 2010) } \\
\hline QCr.usq-2B.2 & 2B: $w P t-5374, \boldsymbol{w P t}-0434$ & & \\
\hline QCr.usq-3B.1 & 3BL: $\boldsymbol{w P t - 7 3 0 1 , w P t - 0 3 6 5}$ & & \\
\hline QCr.usq-4B.1 & 4BS: wPt-4535, Xgwm251 & & \\
\hline Qcr & 7AS: $\boldsymbol{w P t}-\mathbf{4 7 4 8}, w P t-8418$ & & \\
\hline Qcr & 3B: $\boldsymbol{w P t}-1834, w P t-1151$ & 2-49, Aso zairai 11, Ernie & (Li et al. 2010) \\
\hline Qcrs.wsu-3BL & 3BL: Xgwm247, Xgwm299 & \multirow{3}{*}{ Sunco, Macon, Otis } & \multirow{3}{*}{ (Poole et al. 2012) } \\
\hline$Q c r$ & 3BS: $\boldsymbol{w P t}-\mathbf{5 3 9 0}$, Xwmc777 & & \\
\hline Qcr & 7AS: $w P t-3702$ & & \\
\hline Qcrs.cpi-2D & 2DL: $1131013|\boldsymbol{F}| \mathbf{0}, 1246993|F| 0$ & \multirow{4}{*}{ EGA Wylie } & \multirow{4}{*}{ (Zheng et al. 2014) } \\
\hline Qcrs.cpi-4B.1 & 4BS: $\mathbf{1 0 0 0 0 4 3 1 9 |}|\boldsymbol{F}| \boldsymbol{0}, 2324159|F| 0$ & & \\
\hline Qcrs.cpi- $4 B .2$ & 4BS: $\mathbf{1 1 0 8 4 7 2 | F | 0 , 1 0 9 3 6 1 6 | F | 0}$ & & \\
\hline Qcrs.cpi-5D & 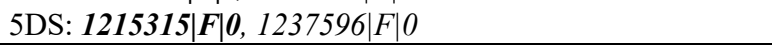 & & \\
\hline \multirow{9}{*}{ Qcr } & 1AS: Xbarc148, Xgwm164 & \multirow{9}{*}{ 2-49, Sunco, IRN497, CPI133817 } & \multirow{9}{*}{ (Martin et al. 2015) } \\
\hline & 1BS: Xcfd65, Xgwm11 & & \\
\hline & 1DL: Xcfd19, Xwmc216 & & \\
\hline & 2A: Xgwm95, Xcfa2043 & & \\
\hline & 2B: Xgwm630, Xcfa2278 & & \\
\hline & 2DS: Xgwm 484, Xgwm 102 & & \\
\hline & 3AL: Xcfa2134, Xcfa2262 & & \\
\hline & 3BL: Xgwm 299, wPt-0021, Xwmc236, wPt-0365 & & \\
\hline & 4BS: Xwmc467, Xgwm165 & & \\
\hline
\end{tabular}




\begin{tabular}{|c|c|c|c|}
\hline & $\begin{array}{l}\text { 4BS: Xbarc193, Xwmc349 } \\
\text { 6DL: Xcfd188, Xcfd47 } \\
\text { 6DL: Xbarc196, Xbarc273 } \\
\end{array}$ & & \\
\hline Qcr & $\begin{array}{l}\text { 2DS: } \boldsymbol{w P t - 6 6 9 5 1 7} \\
\text { 3BS: } w P t-2193, w P t-22988, w P t-732330, \boldsymbol{w P t - 2 7 6 6}\end{array}$ & 2-49, Sunco, Altay-2000 & (Erginbasorakci et al. 2018) \\
\hline $\begin{array}{l}\text { QFCR.heau- } 2 A \\
\text { QFCR.heau- } 2 D \\
\text { Qcr-6AL* } \\
\text { QFCR.heau- } 6 A \\
\text { Qcr- } 6 B \\
\text { Qcr- } 6 D\end{array}$ & 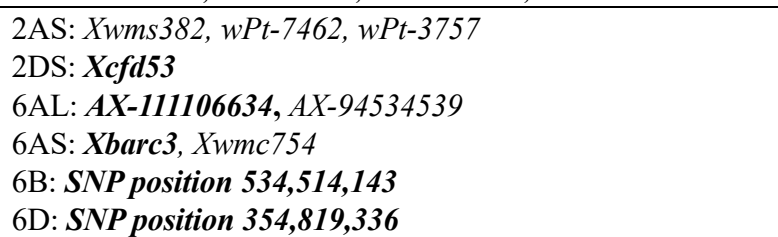 & $\begin{array}{c}\text { Xunmai 118, Kaimai 26, Yanke 316, Xuke } \\
\text { 732, Zhonglemai 9, Jinmai 1, Shenzhou } \\
\text { 209, Fannong 1, Jiyanmai 7, UC1110, } \\
\text { PI610750 }\end{array}$ & (Yang et al. 2019) \\
\hline $\begin{array}{l}\text { TaDIR-B1* } \\
\text { Qcr }\end{array}$ & $\begin{array}{l}\text { 4B: TraesCS4B02G385500 } \\
\text { 4B: } A X-111079978, A X-110977572\end{array}$ & Bainong64 & (Yang et al. 2021) \\
\hline $\begin{array}{c}Q c r \\
Q c r \\
Q c r \\
Q c r \\
Q c r \\
Q c r-5 D L^{*} \\
Q c r \\
Q c r\end{array}$ & $\begin{array}{l}\text { 1BS: } \text { Aff } x-88612017, \text { Aff } x-109495423 \\
\text { 1DS: Aff } x-92108178, \text { Aff } x-109205872 \\
\text { 2AL: Aff } x-111557509 \\
\text { 5DS: Aff } x-88597504, \text { Aff } x-110248324 \\
\text { 5AL: Aff } x-109253960 \\
\text { 5DL: Aff } x-110484766, \text { Aff } x-110079634 \\
\text { 6BS: Aff } x-110282972 \\
\text { 7BL: Aff } x-109846651, \text { Aff } x-109540847\end{array}$ & $\begin{array}{l}\text { Henong 982, Shiyou 17, Bao 6818, } \\
\text { Quanmai 890, 04 Zhong 36, Junda 129, Xu } \\
\text { 10054, Fanmai 5, Lian 0809, Shixin 733, } \\
\text { Shi05-6678, Han 06-5170, Luomai 8, } \\
\text { Zhongyuanzhixing, Yangao 21, Xumai } 33\end{array}$ & (Jin et al. 2020) \\
\hline $\begin{array}{c}Q c r \\
Q c r \\
Q c r / F h b 1^{*} \\
Q c r \\
Q c r \\
Q c r \\
Q c r \\
Q c r \\
Q c r \\
Q c r \\
Q c r \\
Q c r\end{array}$ & 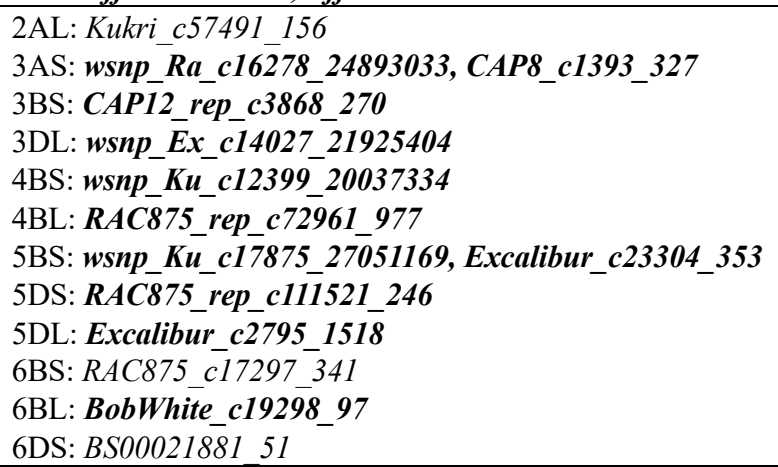 & $\begin{array}{c}\text { VICTORYA, Katea, KOLLEGA, } \\
\text { DORADE-5/3/BOW"S"/GEN//SHAHI, } \\
\text { 2180*K/2163//?/3/W1062A*HVA114/W34 } \\
\text { 16, L 4224 K 12, NE04424, } \\
\text { TX69A509.2//BBY/FOX/3/GRK/NO64/P } \\
\text { EX/4/CER/5/KAUZ//ALTAR 84/AOS, } \\
\text { ID800994.W/MO88 }\end{array}$ & (Pariyar et al. 2020) \\
\hline$Q c r$ & $\begin{array}{l}\text { 1A: BobWhite_c1027_1127, wsnp_Ku_c183_358844 } \\
\text { 1B: BS00070139_51, Tdurum_contig13117_1316 } \\
\text { 1D: wsnp_Ex_c3372_6195001 } \\
\text { 2D: BS00062567_51 }\end{array}$ & $\begin{array}{c}\text { AUS29529/2/2.49/Cunningham//Kennedy/ } \\
\text { 3/Sunco, } \\
\text { CSCR16/2/2.49/Cunningham//Kennedy/3/S } \\
\text { unco/2*Pastor } \\
\end{array}$ & (Rahman et al. 2020) \\
\hline
\end{tabular}


3B: BS00072994_51, BS00079029_51, IACX11310

4A: BS00035307 51

4B: $K \boldsymbol{~ u ~} c 3385 \quad 521$

5B: BS00032003_51, BobWhite_c6094_447

6B: RAC875_c60007_199

7A: BobWhite c33300 159, wsnp JD c1219 1766041

7B: wsnp_be352570B_Ta_2_1
N. A. N. A

Cunmai633, LS4607, Pubing01, Hongyun2,

Jimai216, Fengyunmai5, Huaihe15076,

Luofeng2419, Yanfeng168, Zhengmai22,

Zhoumai38, Zhoumai37, Lemai185,

(Shi et al. 2020)

Xinmai38, Xinong 733, Xinmai45,

Guohemai12, Xinong625, Zhengmai162

Genomic distribution of all these summarized resistant loci were drafted using associated markers and SNPs (bold labeled) that can be found in "Chinese

Spring" wheat genome database. QTLs with major effect or linked with designated genes were labeled with asterisk $(*)$ and highlighted in Fig. 3. 
Supplementary Table 3. Genetic determinants of wheat resistance to sharp eyespot.

\begin{tabular}{|c|c|c|c|}
\hline QTL name & Associated markers or SNPs & Resistant wheat germplasms & Reference \\
\hline $\begin{array}{l}\text { QSe.cau- } 1 A S \\
\text { QSe.cau- } 2 B S \\
\text { QSe.cau- } 3 B S \\
\text { QSe.cau- } 4 A L \\
\text { QSe.cau-5DL } \\
\text { QSe.cau-6BL } \\
\text { QSe.cau-7BL }\end{array}$ & 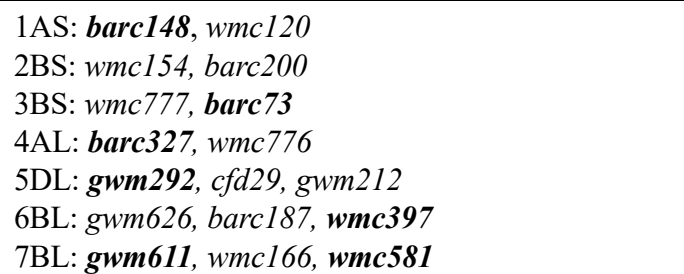 & Luke, AQ24788-83 & (Chen et al. 2013; Guo et al. 2017) \\
\hline $\begin{array}{c}\text { QSe.jaas }-2 B S \\
\text { QSe.jaas }-4 B S \\
\text { QSe.jaas-5AL.1 } \\
\text { QSe.jaas-5AL.2 } \\
\text { QSe.jaas-5BS }\end{array}$ & 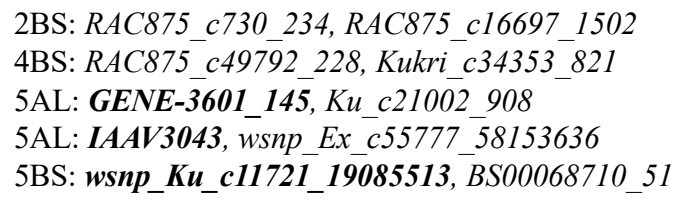 & CI12633 & (Wu et al. 2017) \\
\hline $\begin{array}{l}\text { QSe.jaas-1D* } \\
\text { QSe.jaas }-2 B \\
\text { QSe.jaas-6D } \\
\text { QSe.jaas-7A* } \\
\text { QSe.jaas }-7 D \\
\end{array}$ & $\begin{array}{l}\text { 1D: } \boldsymbol{A X}-111976732, A X-110490771 \\
\text { 2B: } \boldsymbol{A X}-111049538 \\
\text { 6D: } \boldsymbol{A X}-111481557, \boldsymbol{A X}-109521374 \\
\text { 7A: } \boldsymbol{A X}-109911760, A X-110041698 \\
\text { 7D: } \boldsymbol{A X}-110667549, A X-110559985 \\
\end{array}$ & Niavt 14, Xuzhou 25 & (Jiang et al. 2016; Liu et al. 2020) \\
\hline N. A. & N. A. & $\begin{array}{c}\text { Seedling resistance: CI12633, Banmangmai, Banjiemang, Ibis, } \\
\text { Hongyouzi, Shaanhe6, Chinese Spring, Hongxingmai, Pingyuan 50, } \\
\text { Linfen139, Chuanyu12, Yongfengnong2, Yunong202, Xinmai68, } \\
\text { Huabei187, Jinmai50, Neixiang184 } \\
\text { Adult plant resistance: Shaanhe6, CI12633, Banmangmai, Chinese } \\
\text { Spring, Huomai, Banjiemang, Pingyuan50, Pingyang181, Yumai8, } \\
\text { Qingfeng1, Hongyouzi, Hongxingmai, Libellula, Zhengmai8998 }\end{array}$ & (Ren et al. 2020) \\
\hline
\end{tabular}

Genomic distribution of all these summarized resistant loci were drafted using associated markers (bold labeled) that can be found in "Chinese Spring" wheat genome database. QTLs were annotated in Fig. 4. 